\title{
SELETIVIDADE E EFICÁCIA DE HERBICIDAS APLICADOS EM PÓS- EMERGÊNCIA NA CULTURA DO SORGO FORRAGEIRO
}

\author{
ELIANE REGINA ARCHANGELO ${ }^{1}$; ANTÔNIO ALBERTO DA SILVA ${ }^{2}$; JOÃO BAPTISTA DA \\ SILVA $^{3}$; DÉCIO KARAM ${ }^{4}$; ANTÔNIO AMÉRICO CARDOSO ${ }^{2}$
}

\author{
${ }^{1}$ Doutoranda da Universidade Federal de Viçosa, Depto. de Fitotecnia. CEP. 36571-000 Viçosa, MG. E-mail: \\ earchangelo@yahoo.com.br (autor para correspondência) \\ ${ }^{2}$ Prof. do Depto de Fitotecnia da Universidade Federal de Viçosa. CEP. 36571-000 Viçosa, MG. \\ ${ }^{3}$ Secretário Municipal, SMAMADS. CEP. 35701-200, Sete Lagoas. MG. \\ ${ }^{4}$ Pesquisador, Embrapa Milho e Sorgo. Caixa Postal 151, CEP. 35701-970 Sete Lagoas, MG.
}

Revista Brasileira de Milho e Sorgo, v.1, n.3, p.107-115, 2002

\begin{abstract}
RESUMO - Avaliou-se a tolerância da cultura do sorgo forrageiro e o controle de plantas daninhas em relação a diferentes doses de Primestra SC (atrazine $200 \mathrm{~g} \mathrm{~L}^{-1}+$ metolachlor $300 \mathrm{~g} \mathrm{~L}^{-1}$ ) com ou sem adição de óleo mineral (Assist) à calda. Além das testemunhas com e sem capina o experimento constou de 12 tratamentos, constituídos por cinco doses de Primestra $\mathrm{SC}\left(1,5 ; 3,0 ; 6,0 ; 9,0\right.$ e 12,0 $\left.\mathrm{L} \mathrm{ha}^{-1}\right)$, com e sem a adição de Assist (1,5 L ha-1); Gesaprim 500 a 4,8 $\mathrm{L} \mathrm{ha}^{-1}$ (atrazine 2,4 $\mathrm{kg} \mathrm{ha}^{-1}$ ) e Primóleo a 6,0 $\mathrm{L} \mathrm{ha}^{-1}$ \{atrazine + óleo vegetal $(2,4+$ $\left.\left.1,8 \mathrm{~kg} \mathrm{ha}^{-1}\right)\right\}$, aplicados sobre plantas de sorgo forrageiro (AG 2002) com 11 dias após a emergência, plantas daninhas dicotiledôneas com duas a quatro folhas e as monocotiledôneas com um perfilho. Observou-se a recuperação total das plantas de sorgo aos sintomas de toxicidade dos herbicidas. Na testemunha sem capina, verificou-se $24 \%$ de redução na produção de biomassa verde aérea de plantas do sorgo, em comparação à testemunha com capina, enquanto que na biomassa seca não houve redução significativa. O Primestra SC de 6,0 a $12 \mathrm{~L} \mathrm{ha}^{-1}$ proporcionou $98 \%$ de controle de plantas daninhas dicotiledôneas. Todavia, esse herbicida mostrou-se eficiente para o controle de monocotiledôneas, somente a $12 \mathrm{~L} \mathrm{ha}^{-1}$ para obter um controle de $94 \%$. O Gesaprim 500 e o Primóleo promoveram redução no número e na biomassa seca aérea de plantas daninhas dicotiledôneas, em relação à testemunha sem capina, não se verificando, todavia, diferença entre os dois herbicidas. Entretanto, para o controle total de plantas daninhas, o Primóleo foi mais eficiente em relação ao Gesaprim 500. Independente da dose de Primestra SC aplicada, com ou sem adição de Assist, o controle de monocotiledôneas e total de plantas daninhas não diferiu daquele proporcionado pelo Primóleo. A adição de Assist à calda herbicida, no caso de Primestra SC, interferiu negativamente na eficiência de controle de dicotiledôneas, indicando possível antagonismo. Nenhum dos herbicidas avaliados apresentou controle eficiente de monocotiledôneas, com exceção de Primestra SC a $12 \mathrm{~L} \mathrm{ha}^{-1}$, com controle de $94 \%$.
\end{abstract}

Palavras-chave: Tolerância, plantas daninhas, atrazine, metolachlor, Sorghum bicolor

\section{SELECTIVITY AND EFFICACY OF POST EMERGENCE HERBICIDE ON FORAGE SORGHUM}

ABSTRACT - The objective of this study was to determine the selectivity of Primestra SC
$\left(200 \mathrm{~g} \mathrm{~L}^{-1}\right.$ of atrazine $+300 \mathrm{~g} \mathrm{~L}^{-1}$ of metolachlor $)$ on forage sorghum and the efficacy to control
weeds at different rates. The treatments were five rates of Primestra SC $(1,5 ; 3,0 ; 6,0 ;$ and 
12,0 $\left.\mathrm{L} \mathrm{ha}^{-1}\right)$ with or without Assist (mineral oil) at 1,5 $\mathrm{L} \mathrm{ha}^{-1}$, Gesaprim $500\left(500 \mathrm{~g} \mathrm{~L}^{-1}\right.$ of atrazine) at $4,8 \mathrm{~L} \mathrm{ha}^{-1}$, Primóleo ( $400 \mathrm{~g} \mathrm{~L}^{-1}$ of atrazine $+300 \mathrm{~g} \mathrm{~L}^{-1}$ of mineral oil) at $6,0 \mathrm{~L} \mathrm{ha}^{-1}$, weedy check plot, and check plot without weed. The herbicides were sprayed 11 days after sorghum (AG 2002) emergence when broadleaf weeds had two to four leaves and grasses one tiller. Symptoms recovery of herbicide toxicity were detected even when higher rates were applied. Fresh weight reduction of $24 \%$ was observed in the weedy check plot compared to the check plot without weed, however dry matter did not show significantly reduction. Primestra $\mathrm{SC}$ at rates higher than $6,0 \mathrm{~L} \mathrm{ha}^{-1}$ provided excellent broadleaf weed control (98\%). Primestra SC controled efficiently grasses (94\%) at $12 \mathrm{~L} \mathrm{ha}^{-1}$. Gesaprim 500 and Primóleo reduced density and biomass of broadleaf weeds although no significant differences were detected between the herbicides. Primóleo obtained better grass weed control than Gesaprim 500. Grass weed and total weed control did not differ significantly between Primestra SC and Primóleo. The addition of Assist to Primestra SC reduced the efficacy of broadleaf weed control indicating a possible antagonism. None of the evaluated herbicides showed efficient grass weed control except for Primestra SC at 12,0 $\mathrm{L} \mathrm{ha}^{-1}(94 \%)$.

Key words: Tolerance, weed, atrazine, metolachlor, Sorghum bicolor.

A cultura do sorgo apresenta desenvolvimento inicial lento, sendo, por isso, muito susceptível à interferência das plantas daninhas nos primeiros 60 dias após a emergência. A presença de plantas daninhas até a quarta semana após a emergência do sorgo granífero poderá promover redução na produção de 35\% a 70\% (Silva et al., 1988), enquanto que, para o sorgo forrageiro, essa redução pode chegar a 54\% (Khare et al., 1986).

Para essa cultura, são poucos os herbicidas registrados, destacando-se o atrazine $\{6$-cloro-Netil-N'-(1-metiletil)-1,3,5-triazina-2,4-diamina\}, que é recomendado para uso em pré-emergência, podendo, também, ser usado em pós-emergência inicial, quando em formulação apropriada, para o controle de diversas espécies de plantas daninhas dicotiledôneas e algumas gramíneas (Rodrigues \& Almeida, 1998).

Outro herbicida com potencial de uso nessa cultura é o metolachlor \{2-cloro-N-(2-etil-6metilfenil)-N-(2-metoxi-1-metiletil) acetamida\} . Todavia, no Brasil esse herbicida é registrado apenas para as culturas de cana-de-açúcar, feijão, milho e soja (Rodrigues \& Almeida, 1998), enquanto, em outros países, é registrado também para o sorgo, sendo obrigatório o uso de protetores (antídotos) contra esse herbicida. Como não existem protetores registrados no Brasil para as cloroacetamidas, $o$ controle de gramíneas na cultura do sorgo torna-se difícil, pela pouca tolerância desta (Rocchi et al., 1986a e 1986b; Silva et al., 1986; Coelho, 1987; Archangelo et al., 1995; Radosevich et al., 1997). Outra alternativa de uso do metolachlor na cultura do sorgo seria realizar aplicações após a emergência da cultura, porém antes da emergência das plantas daninhas. Nesse estádio de desenvolvimento, as plantas de sorgo tornam-se mais tolerantes a esse herbicida, porque a ação tóxica desse produto acontece durante o processo de emergência das plantas (WSSA, 1994).

Com o objetivo de avaliar a tolerância da cultura do sorgo forrageiro e o controle de plantas daninhas em relação a diferentes doses de Primestra SC (mistura pronta contendo: $200 \mathrm{~g} \mathrm{~L}^{-1}$ de atrazine $+300 \mathrm{~g} \mathrm{~L}^{-1}$ de metolachlor) com ou sem adição de Assist (óleo mineral) à calda, foi conduzido um trabalho na área experimental da Embrapa Milho e Sorgo, em Sete Lagoas, MG, no ano agrícola de 1996/97, em condições de campo. O solo local é classificado como latossolo vermelho distrófico, 
textura argilosa. A precipitação pluviométrica e a temperatura apresentam médias de $1.340 \mathrm{~mm}$ e $22,2^{\circ} \mathrm{C}$, respectivamente. A altitude local é de $732 \mathrm{~m}$.

Foi utilizado o delineamento experimental de blocos casualizados, em esquema fatorial $5 \times 2+4$, com seis repetições, sendo o primeiro fator constituído pelas doses dos herbicidas e o segundo, pelos níveis de óleo mineral. Juntamente com esses dois fatores, foram avaliados quatro tratamentos adicionais: dois herbicidas e duas testemunhas, com e sem capina (Tabela 1).

As parcelas experimentais foram constituídas de seis linhas espaçadas de $0,70 \mathrm{~m}$, com $9,0 \mathrm{~m}$ de comprimento, totalizando $37,80 \mathrm{~m}^{2}$. Foram consideradas como área útil as quatro linhas centrais de cada parcela, excetuando-se 1,0 m de cada extremidade, totalizando $19,60 \mathrm{~m}^{2}$. A adubação de plantio foi de $300 \mathrm{~kg} \mathrm{ha}^{-1}$ da fórmula $8-28-16+0,5 \%$ de Zn. Aos 30 dias após o plantio, fez-se a adubação de cobertura, aplicando-se $44 \mathrm{~kg} \mathrm{ha}^{-1}$ de nitrogênio na forma de sulfato de amônio.
Os herbicidas foram aplicados com pulverizador costal pressurizado a $\mathrm{CO}_{2}\left(4,30 \mathrm{kgf} \mathrm{cm}^{-2}\right)$, equipado com bicos, XR Teejet 110.03 VS, aplicando-se o equivalente a $270 \mathrm{~L} \mathrm{ha}^{-1}$ de calda. $\mathrm{O}$ solo apresentava-se seco na superfície e úmido na subsuperfície, a umidade relativa do ar era de $62 \%$, a temperatura do ar em torno de $38^{\circ} \mathrm{C}$ e a velocidade do vento oscilava entre 1,0 e $3,6 \mathrm{~km} \mathrm{~h}^{-1}$. As aplicações foram realizadas aos 11 dias após a emergência das plantas de sorgo forrageiro (AG 2002), quando essas apresentavam-se com quatro e cinco folhas, as plantas daninhas dicotiledôneas com duas a quatro folhas e as monocotiledôneas (gramíneas) com um perfilho.

O controle de plantas daninhas foi avaliado utilizando-se três amostragens de $0,50 \mathrm{~m}^{2}$, que correspondem a $1,50 \mathrm{~m}^{2} /$ parcela, aos 22 dias após a aplicação (DAA). Avaliou-se, também, aos 83 DAA, a biomassa seca da parte aérea das plantas daninhas por espécie. As avaliações da cultura foram

TABELA 1. Relação dos tratamentos avaliados no experimento.

\begin{tabular}{|c|c|c|c|}
\hline \multirow{2}{*}{ Tratamentos } & \multirow{2}{*}{$\begin{array}{c}\text { Produto Comercial } \\
\text { (p.c.) }\end{array}$} & \multicolumn{2}{|r|}{ Doses } \\
\hline & & $\mathrm{g} \mathrm{ha}^{-1}$ (i.a)* & $\mathrm{L} \mathrm{ha}^{-1}$ (p.c) $* * * *$ \\
\hline (Atrazine+Metolachlor) & Primestra $\mathrm{SC}^{* *}$ & $(300+450)$ & 1,5 \\
\hline (Atrazine+Metolachlor) & Primestra SC & $(600+900)$ & 3,0 \\
\hline (Atrazine+Metolachlor) & Primestra SC & $(1200+1800)$ & 6,0 \\
\hline (Atrazine+Metolachlor) & Primestra SC & $(1800+2700)$ & 9,0 \\
\hline (Atrazine+Metolachlor) & Primestra SC & $(2400+3600)$ & 12,0 \\
\hline (Atrazine+Metolachlor)+óleo mineral & Primestra SC+Assist & $(300+450)$ & $1,5+1,5$ \\
\hline (Atrazine+Metolachlor)+óleo mineral & Primestra SC+Assist & $(600+900)$ & $3,0+1,5$ \\
\hline (Atrazine+Metolachlor)+óleo mineral & Primestra SC+Assist & $(1200+1800)$ & $6,0+1,5$ \\
\hline (Atrazine+Metolachlor)+óleo mineral & Primestra SC+Assist & $(1800+2700)$ & $9,0+1,5$ \\
\hline (Atrazine+Metolachlor)+óleo mineral & Primestra SC+Assist & $(2400+3600)$ & $12,0+1,5$ \\
\hline Atrazine & Gesaprim 500 & 2400 & 4,8 \\
\hline Atrazine+óleo vegetal & Primóleo *** & $(2400)$ & 6,0 \\
\hline Testemunha capinada & - & - & - \\
\hline Testemunha sem capina & - & - & - \\
\hline \multicolumn{4}{|c|}{$\begin{array}{l}\text { * ingrediente ativo. } \\
* * \text { mistura pronta de atrazine }+ \text { metolachlor }\left(200+300 \mathrm{~g} \mathrm{~L}^{-1}\right) . \\
* * * \text { mistura pronta de atrazine }+ \text { óleo vegetal }\left(400+300 \mathrm{~g} \mathrm{~L}^{-1}\right) \\
* * * * \text { produto comercial }\end{array}$} \\
\hline
\end{tabular}


realizadas aos 89 DAA, quando as plantas se encontravam no estádio de grãos pastosos, avaliando-se o estande final, a altura de plantas, o diâmetro do colmo e a produção de biomassa verde e seca da parte aérea do sorgo.

Os resultados obtidos foram submetidos às análises de variância e regressão, ajustando-se modelos polinomiais para as diversas características avaliadas. Na análise de regressão, foi considerado o resultado da testemunha sem capina (dose zero), para ajuste das regressões. As transformações de dados, quando necessárias, foram realizadas conforme recomendações de Steel e Torrie (1960).

Na comparação das médias entre os tratamentos adicionais (testemunhas com e sem capina, Gesaprim 500 e Primóleo), foi utilizado o teste de Duncan, a 5\% de probabilidade e, para a comparação entre ausência e presença de Assist, utilizou-se o teste F. Para a comparação da média da testemunha com cada média dos tratamentos do fatorial, foi utilizado o teste de Dunnett a 5\% de probabilidade.

As espécies de plantas daninhas presentes na área experimental, no momento das aplicações, bem como a intensidade de ocorrência, estão apresentadas na Tabela 2.

Os sintomas iniciais de toxicidade observados nas plantas de sorgo foram clorose, seguidas por manchas necróticas, principalmente nas folhas mais novas. Esses sintomas praticamente desapareceram 28 dias após a aplicação, observando-se desenvolvimento normal das plantas, o que evidencia boa tolerância dessa cultura aos herbicidas avaliados e nas doses estudadas. Resultados semelhantes foram observados por Archangelo et al., (1997) com aplicação de Agimix (atrazine + alachlor), em pós-emergência inicial na cultura do sorgo forrageiro, nas doses de 3,0 e 4,0 $\mathrm{L} \mathrm{ha}^{-1}$ do produto comercial com e sem adição de 1,5 $\mathrm{L} \mathrm{ha}^{-1}$ de Ankor (óleo vegetal).
TABELA2. Principais plantas daninhas presentes no experimento e suas intensidades de ocorrência por ocasião da aplicação dos tratamentos

\begin{tabular}{|c|c|}
\hline Espécies & 1.O, ${ }^{*}$ \\
\hline Richardia brasiliensis Gomez (poaia-branca) & $\mathrm{D}$ \\
\hline Raphowus raphonistram L. (nabiça) & D \\
\hline Amananthus spp. L. (carunu) & S \\
\hline Bidens pilosa L. (pictio-preto) & S \\
\hline Portuloca oleracea L. (beldroega) & E \\
\hline Nicandra physcaloxides Gaertn. (Goí-de-capote) & E \\
\hline Eapphorbia heterophylla L. (leiteiro) & E \\
\hline Sida mombifolia L. (guanxuma) & E \\
\hline Acanthospermim hispidim DC. (carrapicho-cameiro) & $\mathrm{E}$ \\
\hline Brochiarla plarriaginea (Link) Hitche (capim-marmelada) & D \\
\hline Cenchrnes echimarus L. (capim-carrapicho) & D \\
\hline Digitária horizontalis Willd (capim-colchāo) & S \\
\hline Eleusine indica (L.) Gaertn (capim-pé-de-galinha) & $\mathrm{E}$ \\
\hline
\end{tabular}

* (Intensidade de Ocorrência) $\mathrm{D}=$ Dominante, $\mathrm{S}=$ Secundária, $\mathrm{E}=$ Esporádica

Para estande final, altura de plantas, diâmetro do colmo e produção da biomassa seca da parte aérea de plantas de sorgo, aos 89 DAA, não foram observadas diferenças significativas entre as doses de Primestra SC, obtendo-se as seguintes médias: 243.502 plantas ha-1, $200 \mathrm{~cm}, 1,3 \mathrm{~cm}$ e $11 \mathrm{t} \mathrm{ha}^{-1}$, respectivamente. Para a biomassa verde da parte aérea, verificou-se o efeito linear das doses do Primestra SC. Nas maiores doses do Primestra SC, obtiveram-se as maiores produções de biomassa verde de sorgo (Figura 1). Isso pode ser explicado pelo fato de o Primestra SC ter apresentado, nas maiores doses, melhor controle das plantas daninhas infestantes, reduzindo a interferência com as plantas de sorgo, possibilitando, assim, expressar melhor o seu potencial produtivo.

A produção de biomassa verde da parte aérea de plantas de sorgo não diferiu entre os tratamentos com Gesaprim 500, Primóleo e testemunha capinada. Apenas na testemunha sem capina observou-se $24 \%$ de redução na produção de biomassa verde aérea de plantas do sorgo, em comparação à testemunha com capina (Tabela 3). Essa redução, 
segundo Everaarts (1993), pode estar associada à ocorrência de uma infestação moderada de plantas daninhas na área experimental. Em culturas com altas infestações de plantas daninhas, essa redução pode alcançar valores de até 70\% (Silva et al., 1986), em sorgo granífero, e acima de $54 \%$ (Khare et al., 1986) em sorgo forrageiro.

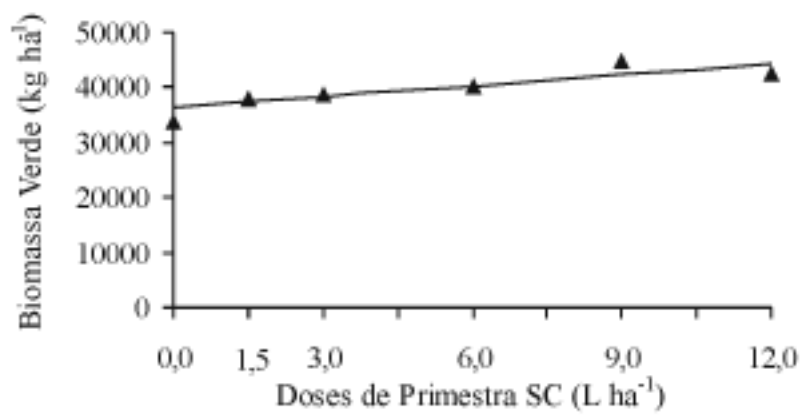

FIGURA 1. Biomassa verde da parte aérea, de plantas de sorgo forrageiro (AG 2002), em resposta às doses de Primestra SC, avaliada aos 89 dias após aplicação

Quanto à eficiência de controle, observase, na Figura 2, que, com o Primestra SC, na dose recomendada $\left(6,0 \mathrm{~L} \mathrm{ha}^{-1}\right)$, obtiveram-se quatro plantas $/ 1,50 \mathrm{~m}^{2}$, de dicotiledôneas, o que equivale a um controle de $98 \%$ em relação à dose zero, que apresentou o maior valor, 198 plantas $/ 1,50 \mathrm{~m}^{2}$.
Todavia, considerando a eficiência de controle do Primestra SC sobre o controle de monocotiledôneas, aos 22 DAA (Figura 2), observou-se, para a dose zero, 53 plantas $/ 1,50 \mathrm{~m}^{2}$, e, para a maior dose, 12 plantas $/ 1,50 \mathrm{~m}^{2}$, equivalendo a um controle de $77 \%$, considerado não satisfatório. Estes resultados evidenciam que o Primestra SC, até mesmo no dobro da dose recomendada, não foi eficiente para o controle de gramíneas em estádio avançado de desenvolvimento (um perfilho).

Quanto à eficiência no controle total de plantas daninhas (gramíneas + dicotiledôneas), aos 22 DAA (Figura 2), verificou-se melhora do controle com o aumento das doses de Primestra SC, chegando a 95\%, quando aplicou-se $12,0 \mathrm{~L} \mathrm{ha}^{-1}$. É importante ressaltar que essa eficiência foi observada devido às dicotiledôneas serem mais susceptíveis ao produto e de maior incidência dessas na área experimental (Tabela 2).

Considerando apenas a eficiência de controle para as dicotiledôneas, verificou-se, aos 83 DAA (Figura 3), o maior valor de biomassa seca da parte aérea, $40,95 \mathrm{~g} / 1,50 \mathrm{~m}^{2}$, na dose zero, e o valor mínimo estimado, ou seja, maior eficiência de controle $\left(99 \%\right.$ ou $\left.0,56 \mathrm{~g} / 1,50 \mathrm{~m}^{2}\right)$, quando, através da equação ajustada, aplicaram-se 7,31 L ha ${ }^{-1}$ de

TABELA 3. Médias relativas a estande final, altura de plantas, diâmetro do colmo e biomassa verde e seca da parte aérea, avaliadas aos 89 dias após aplicação, em resposta aos tratamentos aplicados em sorgo forrageiro (AG 2002).

\begin{tabular}{|c|c|c|c|c|c|c|}
\hline \multirow{2}{*}{ Tratamentos } & \multicolumn{3}{|c|}{$22 \mathrm{DAA}$} & \multicolumn{3}{|c|}{83 DAA } \\
\hline & D & $\mathbf{M}$ & T.P.D. & D & $\mathbf{M}$ & T.P.D. \\
\hline Primestra SC s/ Assist & $10,43 b^{*}$ & 41,18 & 54,85 & $0,94 \mathrm{~b}$ & 19,99 & 21,64 \\
\hline Primestra SC c/ Assist & $16,53 \mathrm{a}$ & 38,33 & 57,98 & $1,58 \mathrm{a}$ & 21,62 & 23,86 \\
\hline
\end{tabular}

*Médias dos tratamentos adicionais seguidas pela mesma letra na coluna não diferem entre si a 5\%, pelo teste de Duncan. 
Primestra SC. Todavia, esse herbicida mostrou-se eficiente para o controle das monocotiledôneas somente a $12 \mathrm{~L} \mathrm{ha}^{-1}$, para obter um controle de $94 \%$.

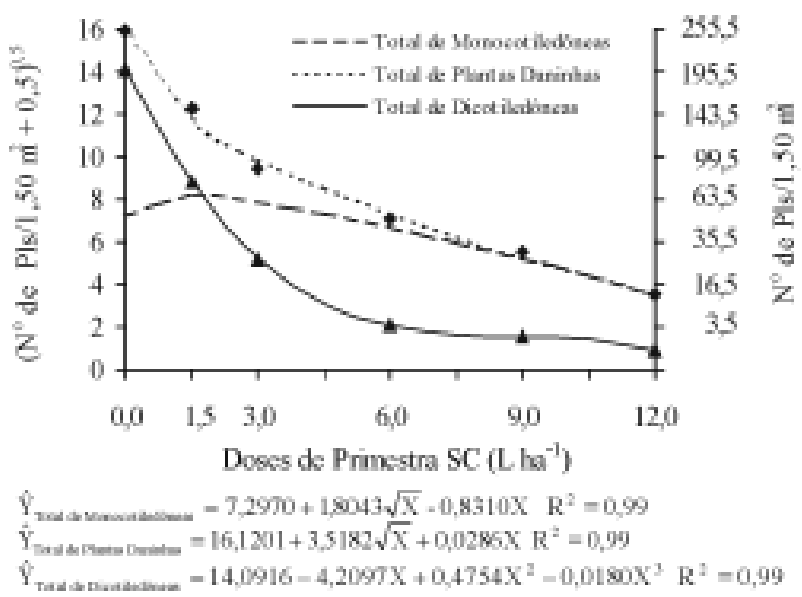

FIGURA 2. Número de monocotiledôneas, de dicotiledôneas e total de plantas daninhas $/ 1,50 \mathrm{~m}^{2}$, em resposta às doses de Primestra $\mathrm{SC}$, avaliados aos 22 DAA (dados transformados em $\sqrt{x+0,5} \mathrm{e}$ destransformados).

O uso de altas doses de herbicida, além de aumentar o impacto ambiental, prolongando a permanência de resíduo no solo, segundo Rajagopal (1988) e Ferris et al. (1989), invibializa economicamente o manejo das plantas daninhas na cultura do milho.

Resultados semelhantes foram observados para o controle total de plantas daninhas (dicotiledôneas + gramíneas) aos 83 DAA (Figura 3), verificando-se que a biomassa seca da parte aérea/ $1,50 \mathrm{~m}^{2}$ foi de $97,50 \mathrm{~g}$, na dose zero, e a menor biomassa seca da parte aérea foi $6,68 \mathrm{~g}$, equivalente ao controle de $93 \%$ na dose de $12,0 \mathrm{~L} \mathrm{ha}^{-1}$ de Primestra SC.

A adição de Assist à calda herbicida reduziu a eficiência de controle de dicotiledôneas, aos 22 e 83 DAA (Tabela 4), indicando possível antagonismo. Tal fato não ocorreu com as monocotiledôneas. Esses resultados, aliados ao aumento da toxicidade à cultura do sorgo, indicam que não há necessidade da adição do Assist em mistura no tanque com Primestra SC, para as condições deste experimento.

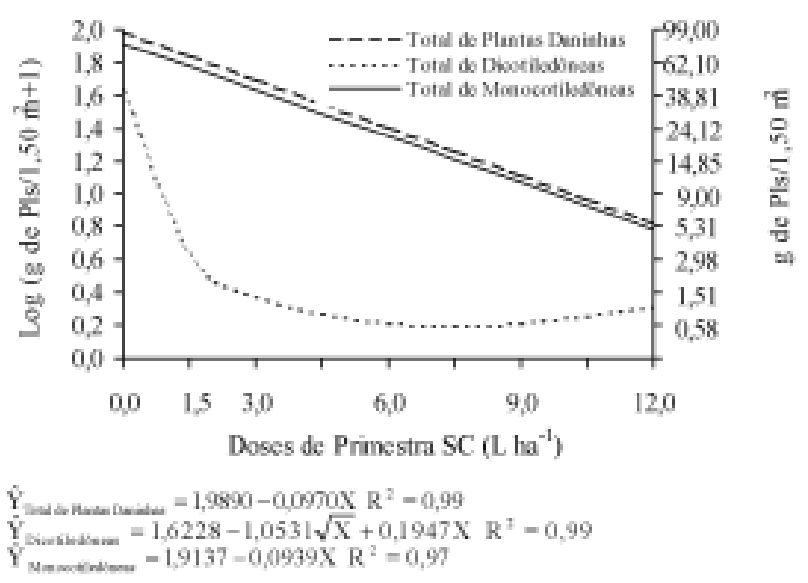

FIGURA 3. Biomassa seca da parte aérea, em gramas $/ 1,50 \mathrm{~m}^{2}$, de dicotiledôneas, monocotiledôneas $\mathrm{e}$ total de plantas daninhas, em resposta às doses de Primestra SC, avaliadas aos 83 DAA (dados transformados em $\log (\mathrm{x}+1)$ e destransformados).

Quanto à eficiência de controle das plantas daninhas, promovida pelos herbicidas-padrões (testemunhas adicionais) (Tabela 5), verifica-se que tanto o Gesaprim 500 quanto o Primóleo causaram redução no número e na biomassa seca de plantas daninhas dicotiledôneas, em relação à testemunha sem capina, sem diferenças significativas entre os dois herbicidas. Porém, esses tratamentos não apresentaram controle eficiente de monocotiledôneas, não se observando diferenças entre estes e a testemunha sem capina. Esses resultados discordam dos obtidos por Velini et al. (1993), os quais observaram que o atrazine, em mistura com óleo vegetal (Primóleo), aplicado aos 12 dias após emergência do milho, promoveu bom controle de $B$. plantaginea, em avaliações realizadas aos 18 e 48 DAA.

Verifica-se, ainda, na Tabela 5, que houve melhor eficiência do Primóleo em relação ao Gesaprim 500, para o controle total de plantas 
TABELA 4. Médias do número de plantas/1,50 $\mathrm{m}^{2}$ avaliadas aos 22 DAA e da biomassa seca da parte aérea, em gramas $/ 1,50 \mathrm{~m}^{2}$, avaliadas aos 83 DAA, de dicotiledôneas (D), monocotiledôneas (M) e total de plantas daninhas (T.P.D), em resposta a Primestra SC sem e com adição de Assist à calda.

\begin{tabular}{lcccccccc}
\hline \multirow{2}{*}{ Tratamentos } & \multicolumn{3}{c}{ 22 DAA } & & \multicolumn{3}{c}{ 83 DAA } \\
\cline { 2 - 3 } \cline { 8 - 9 } & D & M & T.P.D. & & D & M & T.P.D. \\
\hline Primestra SC s/ Assist & $10,43 \mathrm{~b}^{*}$ & 41,18 & 54,85 & & $0,94 \mathrm{~b}$ & & 19,99 & 21,64 \\
Primestra SC c/ Assist & $16,53 \mathrm{a}$ & 38,33 & 57,98 & & $1,58 \mathrm{a}$ & 21,62 & 23,86 \\
\hline
\end{tabular}

*Médias seguidas por letras diferentes diferem significativamente pelo teste $\mathrm{F}$, a 5\% de probabilidade.

TABELA 5. Médias do número de plantas/1,50 $\mathrm{m}^{2}$ avaliadas aos 22 DAA e da biomassa seca da parte aérea, em gramas $/ 1,50 \mathrm{~m}^{2}$, avaliadas aos $83 \mathrm{DAA}$, de dicotiledôneas (D), monocotiledôneas (M) e total de plantas daninhas (T.P.D.), em resposta aos diferentes tratamentos.

\begin{tabular}{|c|c|c|c|c|c|c|c|}
\hline \multirow{2}{*}{ Tratamentos } & \multirow{2}{*}{ Doses $\mathrm{L} \mathrm{ha}^{-1}$} & \multicolumn{3}{|c|}{22 DAA } & \multicolumn{3}{|c|}{83 DAA } \\
\hline & & D & M & T.P.D. & D & $\mathbf{M}$ & T.P.D. \\
\hline Primestra SC & 1,5 & $60,36(+)^{*}$ & 78,7 & $144,38(+)$ & $2,92(+)$ & 74,66 & 79,22 \\
\hline Primestra SC & 3,0 & $18,83(+)$ & 66,68 & $88,95(+)$ & 0,57 & 43,24 & 45,24 \\
\hline Primestra SC & 6,0 & 3,95 & 47,84 & 52,36 & 0,49 & 22,64 & 24,18 \\
\hline Primestra SC & 9,0 & 1,24 & 22,21 & 23,67 & 0,66 & 6,76 & 8,76 \\
\hline Primestra SC & 12,0 & 0,31 & 11,52 & $11,86(-)$ & 0,81 & 5,65 & 7,83 \\
\hline PrimestraSC+Assist & $1,5+1,5$ & $95,67(+)$ & 59,29 & $158,07(+)$ & $5,10(+)$ & 43,3 & 49,6 \\
\hline PrimestraSC + Assist & $3,0+1,5$ & $35,33(+)$ & 53,77 & $90,56(+)$ & 1,54 & 56,08 & 59 \\
\hline PrimestraSC + Assist & $6,0+1,5$ & 4,15 & 42,89 & 47,81 & 0,86 & 30,54 & 32,74 \\
\hline PrimestraSC + Assist & $9,0+1,5$ & 2,54 & 35,16 & 38,33 & 0,87 & 15,29 & 17,35 \\
\hline PrimestraSC + Assist & $12,0+1,5$ & 0,38 & 11,73 & $12,22(-)$ & 1,15 & $3,56(-)$ & 5,71 \\
\hline Gesaprim 500 & 4,8 & $2,20 b^{* \hbar}$ & $72,63 \mathrm{a}$ & $75,56 \mathrm{~b}$ & $0,79 b$ & 36,41 & $37,22 \mathrm{ab}$ \\
\hline Primóleo & 6,0 & $1,6 \mathrm{lb}$ & $39,98 \mathrm{~b}$ & $42,51 \mathrm{c}$ & $0,58 \mathrm{~b}$ & 22,36 & $23,68 \mathrm{~b}$ \\
\hline Test. s/capina & - & $198,41 \mathrm{a}$ & $52,97 \mathrm{ab}$ & $252,69 \mathrm{a}$ & $39,46 a$ & 55,27 & $103,23 \mathrm{a}$ \\
\hline
\end{tabular}

*Médias seguidas por (+) e (-) foram, respectivamente, superiores ou inferiores ao Primóleo, a 5\% de probabilidade, pelo teste de Dunnett.

**Médias dos tratamentos adicionais, seguidas pela mesma letra, na mesma coluna, não diferem significativamente pelo teste de Duncan, a 5\% de probabilidade.

daninhas, aos 22 e 83 DAA, confirmando resultados obtidos por Velini et al. (1993), Karam et al. (1995a) e Karam et al. (1995b).

Quando se compara a eficiência do tratamento padrão (Primóleo), com o Primestra SC com e sem adição de Assist, na redução do número de plantas por 1,5 $\mathrm{m}^{2}$, observa-se (Tabela 5) que, para o controle de dicotiledôneas e total de plantas daninhas aos 22 DAA, apenas as doses de Primestra $\mathrm{SC}$, iguais ou superiores a $6,0 \mathrm{~L} \mathrm{ha}^{-1}$, promoveram controles semelhantes ao do Primóleo. Todavia, no acúmulo de biomassa seca, o controle 
de dicotiledôneas aos 83 DAA, as doses de 3,0 a $12,0 \mathrm{~L} \mathrm{ha}^{-1}$, com e sem adição de Assist, promoveram controle semelhante ao do Primóleo. No entanto, independente da dose de Primestra SC, aplicada com ou sem adição de Assist, o controle de plantas daninhas monocotiledôneas aos 22 DAA e 83 DAA e total de plantas daninhas aos 83 DAA não diferiu do Primóleo $\left(6,0 \mathrm{~L} \mathrm{ha}^{-1}\right)$, pelo teste de Dunnett, a $5 \%$ de probabilidade.

O herbicida Primestra SC, aplicado em pósemergência, pode ser considerado uma alternativa de controle químico de plantas daninhas para a cultura do sorgo forrageiro, embora ainda haja necessidade de seu registro junto ao Ministério da Agricultura, Pecuária e Abastecimento. Salienta-se que a adição de óleo mineral agrava os sintomas de fitotoxicidade, reduzindo a seletividade da cultura do sorgo forrageiro para com o herbicida Primestra SC.

\section{Literatura Citada}

ARCHANGELO, E.R.;SILVA, J.B.; DUARTE, N.F. Controle seletivo de plantas daninhas na cultura do sorgo forrageiro com a mistura formulada de alachlor + atrazine em pós-emergência inicial. In: CONGRESSO BRASILEIRODA CIÊNCIA DAS PLANTAS DANINHAS, 21, 1997, Caxambu. Resumos... Viçosa: SBCPD, 1997. p. 232.

ARCHANGELO, E.R.; SILVA, J.B.; KARAM, D. Controle pós-emergente de plantas daninhas na cultura do sorgo granífero com a mistura atrazine + metolachlor. In: CONGRESSO BRASILEIRODA CIÊNCIA DAS PLANTAS DANINHAS, 20, 1995, Florianópolis. Resumos... Florianópolis: SBCPD, 1995. p.180-182.

COELHO, J.P. Efeitos de antídotos na atividade das cloroacetanilidas sobre as plantas de sorgo (Sorghum bicolor (L.) Moench). 1987. $70 \mathrm{f}$. Tese (Mestrado em Fitotecnia) - Universidade Federal de Viçosa, Viçosa.
EVERAARTS, A. P. Effects of competition with weeds on the growth, development and yield of sorghum. Journal of Agricultural Science, Cambridge, v. 120, p.187-196, 1993.

FERRIS, I.G.; FELTON, W.L.; HOLLAND, J.F.; BULL, M.S. Effect of tillage practice on the persistence of atrazine in two contrasting soil in Northern New South Wales. Australian Journal of Experimental Agriculture, East Melbourne, v. 29, p.849-853, 1989.

KARAM, D.; ARCHANGELO, E.R.; SILVA, J.B. Manejo de plantas daninhas na cultura da milho, com a utilização de herbicidas de diferentes modalidades e aplicação sequencial de paraquat In: CONGRESSO BRASILEIRO DA CIÊNCIADAS PLANTAS DANINHAS, 20, 1995, Florianópolis. Resumos... Florianópolis: SBCPD, 1995(a). p.172-174.

KARAM, D.; SILVA, J.B.; ARCHANGELO, E.R. Controle pós-emergente de plantas daninhas na cultura do milho em diferentes épocas de aplicação. In: CONGRESSO BRASILEIRO DA CIÊNCIA DAS PLANTAS DANINHAS, 20, 1995, Florianópolis. Resumos... Florianópolis: SBCPD, 1995(b). p.180-182.

KHARE, P.D.; SHARMA, S.M.; TIWARI, D.P.; RATHORE, R.S. Nutrients uptake by forage sorghum and weeds as affected by herbicides. Indian Journal of Weed Science, v. 18, p.231-237, 1986.

RADOSEVICH, S.; HOLT, J.; GHERSA, C. Herbicide use and application. In: RADOSEVICH, S.; HOLT, J.; GHERSA, C (Ed.). Weed ecology; implications for management. New York: J. Wiley, 1997. p.398-444.

RAJAGOPAL, V. Effect of atrazine on nutrient uptake by sorghum as influenced by seasons, soils and fertility levels. Journal of Research Apau, Apau, v.16, n. 2, p.102-107, 1988. 
ROCCHI, C.E.; GANDOLFI, V.H.; CUNHA, G.R.; CHILlE, Z. Avaliação dos herbicidas acetoclor, alaclor, metolaclor e metazacloro no controle de invasoras do sorgo sacarino (Sorghum bicolor (L.) Moench). In: REUNIÃO TÉCNICA ANUAL DO SORGO, 13, 1984, Pelotas. Anais... Pelotas: EMBRAPA-CNPATB, 1986(a). p.95-105.

ROCCHI, C.E.; GANDOLFI, V.H.; CUNHA, G.R.; CHILLE, Z. Toxicidade do Metolaclor às duas cultivares de sorgo (Sorghum bicolor (L.) Moench) e efeitos antidotais do $\mu$-(1,3-Dioxoloan-2-ylmetoxi)-imino-benzeno acetonitrila usado como tratamento de semente. In: REUNIÃO TÉCNICA ANUAL DO SORGO, 13, 1984, Pelotas. Anais... Pelotas: EMBRAPA-CNPATB, 1986(b). p.79-93.

RODRIGUES, B.N.; ALMEIDA, F. S. Guia de herbicidas. 4. ed. Londrina: IAPAR, 1998. 648p.

SILVA, J.B.; PASSINI, T.; VIANNA, A.C. Controle de plantas daninhas na cultura do sorgo. Informe Agropecuário, Belo Horizonte, v.12, n.144, p. 43-45, 1986.

SILVA, J.B.; PASSINI, T.; VIANNA, A.C. Controle de plantas daninhas na cultura do sorgo. In:
EMBRAPA - Centro Nacional de Pesquisa de Milho e Sorgo. Recomendações técnicas para o cultivo do sorgo. Sete Lagoas, 1988. p.41-43. (EMBRAPA-CNPMS - Circular Técnica, 1).

STEEL, R.G.D.; TORRIE, J.H. Analysis of variance II: multiway classifications. In: STEEL, R.G.D., TORRIE, J.H. (Ed.) Principles and procedures of statistics with special reference to the biological sciences. New York: McGraw-Hill, 1960. p. 132-160.

VELINI, L.A.; FREDERICO, S.J.; BICUDO, U.R.; ANTUNIASSI, U. R. Eficiência de herbicidas pré e pós-emergentes iniciais recomendados para a cultura do milho, no controle de plantas daninhas e avaliação de efeitos dos mesmos sobre a produtividade da cultura. In: CONGRESSO BRASILEIRO DE HERBICIDAS E PLANTAS DANINHAS, 19, 1993, Londrina. Resumos... Londrina: IAPAR, 1993. p. 141-142.

WEED SCIENCE SOCIETY OF AMERICA. Herbicide handbook. 7. ed. Champaign, 1994. $352 \mathrm{p}$. 